\title{
LA MUJER: UNA VISIÓN DE ÉPOCA. DE LA NECESARIA DOCUMENTACIÓN HISTÓRICA (1800-1859)
}

\author{
Sara Pujol RusSell \\ Universitat Rovira i Virgili
}

Al enfrentarme a la lectura de la poesía femenina del siglo XIX en general y del Romanticismo en particular, me viene al recuerdo la afirmación de Ortega y Gasset: «El hombre que conserva la fe en el pasado no se asusta del porvenir, porque está seguro de encontrar en aquél la táctica, la vía, el método para sostenerse en el problemático mañana»'. Me pregunto en qué tradición del pasado, en qué tradición femenina del pasado puede sostenerse la concepción femenina como individuo creador, como individuo ideológico, como individuo creador de pensamiento y arte; y no como retrato artístico, no como elemento decorativo de una sociedad que aquilata su virtud con su belleza, su virtud con su silencio, su belleza con el estricto cumplimiento de su función doméstica, benéfica y social. Ser pintada, pero no pintar, ser contada, pero no contar, o cantar canciones ligeras y livianas alejadas del esplendoroso fruto del sentir y el pensar, peligroso fruto para el hombre, único depositario de los bienes del pensamiento y el arte. ¿En qué tradición y en qué inmediatez cultural, religiosa, estética se sustenta la poesía femenina del siglo XIX? ¿En qué tradición se sustenta la poesía femenina del siglo XX? Comprender la poesía femenina del siglo XIX y sus circunstancias es aproximarnos a un intento de comprensión del mundo femenino de nuestro siglo $\mathrm{XX}$ y un intento de comprensión de la esencia y evolución de la poesía femenina en ese periodo $\mathrm{y}$ en la actualidad.

1 José Ortega y Gasset: Carta a un alemán pidiendo un Goethe desde dentro, Madrid, Biblioteca Nueva, Fundación Ortega y Gasset, 2004 [1932], pág. 43. 
He leído mucha poesía femenina del siglo XIX, de la que caben hacerse diferentes juicios de valor, y mucha de ella sigue siendo ignorada e incomprendida, otra, denostada por juicios de valor excluyentes de antemano por no saber deducir la lección moral, humana y social que se desprende de cada verso escrito. Si la historia de la literatura se escribe a partir de valores presupuestos, la historia del pensamiento debe escribirse no a partir de unos pocos modelos que alguien elige como tributo de la historia literaria, sino a partir de la consideración de una amplia manifestación de textos que nos ofrecen en sus páginas el ser de una época. Ignorarlos es traicionarnos en aras de lo sublime, en aras de la ignorancia que nos justifica en nuestra incomprensión del pasado y del presente.

No hablo de redención feminista - nada más alejado de mis propósitos-, sino de comprensión histórica. De las múltiples fuentes desde las que se puede escribir la historia del pensamiento, la poesía, sobre todo la de la época moderna, y más concretamente la femenina, es una de ellas. El comportamiento del poema es forma ideológica y respuesta social. Una poesía a veces elemental, a veces oculta bajo códigos de factura simbólica -todavía por estudiar e interpretar debidamente, que por su apariencia de engañosa levedad ha originado una crítica fácil que no ha sabido dotar de significados al sentido metafórico del que estaba dotada en su época-, pero siempre impregnada de una densa problemática vital a tenor de las circunstancias de su siglo y a tenor del muro que se levanta ante la mujer escritora, sobre todo ante la mujer poeta, porque si los logros de prosistas pueden llegar a ser celebrados parece que, por el contrario, la misma naturaleza de la poesía lírica es inherentemente incompatible con la naturaleza o esencia del carácter y composición física e intelectual femenina, y todo ello debido a que la poesía es un género elevado y noble cuyos temas centrales, Dios, el destino, el tiempo, la misma esencia de la poesía, la libertad, el amor, la integridad, el ser, la existencia son vedados a la escritura femenina, y son vedados de forma social pero, al mismo tiempo, y esto es lo terrible, son vedados de forma sutil bajo argumentaciones teóricas y pretendidamente científicas que aspiran a afianzarse en la conciencia de todos acerca de la incapacidad de la mujer para pensar de forma racional y elevada. El espacio que se le deja es el del sentimiento encauzado en los valores religiosos tradicionales, el canto liviano, y la autorrenuncia y el silencio. La mujer del XIX es vilipendiada, la mujer vive atrapada, encerrada, negada, sofocada bajo el peso de su pensamiento y el pensamiento social que se le impone.

La mujer en su ser mismo, en su existencia como individuo y como ser social, el derecho de la mujer a optar a una educación funcional o una formación intelectual, el derecho de la mujer -o lo que es peor, las posibilidades de la mujer en su ser y sustancia femenina- al ejercicio de la escritura -no a su dedicación a la literatura--, al ejercicio de la ciencia o el arte se convierten en tema de debate a lo largo de un siglo. De ese debate extraemos la estructura ideológica de un país, 
fijamos uno de los eslabones de la historia del pensamiento social, filosófico y literario, $y$, sobre todo, nos damos la posibilidad de una comprensión abierta de la poesía femenina del Romanticismo, del siglo XIX en general y, también, de la poesía del siglo XX.

La selección bibliográfica que propongo es a modo de invitación al conocimiento antes de adentramos en la lectura y estudio de la poesía escrita por mujeres, para dotarnos, así, de la permeabilidad necesaria para comprender y valorar los temas y formas de su producción; para comprender el complejo proceso de la elaboración del pensamiento femenino; para comprender la formación de la conciencia femenina de la modernidad, una conciencia y un pensamiento que evolucionan no en sentido lineal y progresivo, sino en crestas de evolución, involución y, de nuevo, evolución, tanto si tenemos en cuenta el pensamiento de una autora determinada a lo largo de su vida, como si consideramos el movimiento del pensamiento a lo largo de un siglo. Por todo ello, me ciño a los artículos y obras que se centran en el ser y esencia femenina, en la educación de la mujer, y en la mujer como ser susceptible de crear literatura y como ser pensante, atendiendo tanto a la voz masculina como a la femenina, tanto a los defensores de la educación de la mujer y su condición espiritual para la creación, los menos, como a los detractores, los más.

Esta selección se ha realizado con criterios de rigor basados en la relevancia del autor, la importancia de la publicación donde aparece el texto, o por la repercusión social -muchos de ellos, auténtico legado en la construcción ideológica- que tuvieron en su momento histórico.

Se abarcan obras publicadas en España, recogiendo también aquellas traducciones españolas de obras europeas que se convirtieron en fuente programática e hito social y cultural en el desarrollo o el constreñimiento ideológico de nuestro país.

En el caso de los libros, suelo citar por la primera edición o, en su defecto, por la edición que mayor repercusión tuvo en su momento, o cuando hay problemas actuales de localización de la obra por la edición más asequible en bibliotecas, haciendo constar, cuando la conozco, la primera edición, como notificación adicional, y lo mismo vale para las traducciones. Sólo hago constar ediciones posteriores de una obra cuando son realmente significativas, por su carácter o por su número, y cuya constatación aporta datos relevantes en la transmisión del pensamiento.

Por lo que respecta a los artículos, es posible encontrar un mismo estudio en varias publicaciones, en ese supuesto hago constar los casos que he detectado valorando la importancia histórica del texto.

El periodo de acotación temporal que he fijado, entre 1800 y 1859 , con algunas referencias de interés relevante anteriores a 1800 , tiene la voluntad de 
ofrecer los textos -desde este particular punto de vista que complementa los otros presupuestos ideológicos, sociales, religiosos, estéticos, literarios...- que conocidos y tenidos en cuenta en su totalidad se erigen en fuente imprescindible para la comprensión de la poesía femenina o masculina o del arte en general, de un ciclo en el que se inicia, cuaja y disuelve el espíritu del Romanticismo como forma de vida, como forma artística y como forma literaria. 


\section{BIBLIOGRAFÍA}

A.G., 1840. «Las mujeres», El Nacional, 17, 18 y 20 de diciembre.

B.A. M. F., 1846. «Pinceladas históricas sobre la educación de la mujer», Atenas, págs. 274-279.

«A nuestras suscriptoras», Gaceta del Bello Sexo, 8 de diciembre de 1851.

ACEBAl [Y DE ROCHEMBEAU], David, 1857. «Defensa de las mujeres», Semanario Pintoresco Español, págs. 229-230.

AIMÉ-MARTIN, L., 1842, 1859 y 1863. Educación de las madres de familia o de la civilización del linaje humano por medio de las mujeres, Barcelona, 2 vols.

Alemany, L[orenzo], 1853. Defensa de las mujeres, por... Escrita en contraposición de los Cuadros o Historia del matrimonio que publicó D. Antonio Flores, Valladolid, Imp. de D. José María Lezcano y Roldán.

AMAR Borbón, Josefina, 1784-1785. «Discurso en defensa del talento de las mujeres y de su actitud para el gobierno y otros cargos en que se emplean los hombresy en Memorial literario, instructivo y curioso de la Corte de Madrid, Madrid.

- 1790. Discurso sobre la educación fisica y moral de las mujeres, Madrid, Imp. de D. Benito Cano.

- 1784. Importancia de la instrucción que conviene dar a las mujeres, Zaragoza, Blas Mieres.

AmARITA, León, 1822. «Discurso Preliminar. A las señoras», El Periódico de las Damas, núm. 1.

- 1822. «Sobre el deseo de agradar y parecer bien de las mujeres», El Periódico de las Damas, núm. 3.

- 1822. «Sobre el influjo de las mujeres en la sociedad», El Periódico de las Damas, núm. 4.

- 1822. «Cartas de una madre a una hija que va a tomar estado», El Periódico de las Damas, núm. 6.

- 1822. «Contestación a una dama», El Periódico de las Damas, núm. XXIV, págs. 10-21.

A[RIBAU, B. C.] (?). «Sobre la educación de las niñas», El Europeo, vol. III, núm. 16 , págs. 121-125.

BARCIA, Roque, 1858. «La mujer (estudio filosófico)», La América, t. II, núm. 16 , pág. 9.

BASCO FLANCAS, R, 1727. Apoyo a la defensa de las mujeres que escribió el R.P. Fray Benito G. Feijoo y crisis de la contradefensa critica, que a favor de los hombres, y contra las mujeres, dio a luz temerariamente D. Laureano Manco de Olivares, Madrid.

«Buen nombre obliga, Un», Album de Señoritas, 23 de marzo de 1852. 
C., 1836. «Importancia del bello sexo», El Guardia Nacional, núm. 121, 26 de marzo, págs. 1-2.

CABEZA, Felipa Máxima de y CABEZA, M. ${ }^{a}$ Paula de, 1855. La señorita instruida o sea Manual del bello sexo. (Texto para las escuelas femeninas), [s.1.], [s.i.], 1854-1855, 2 vols.; Madrid, Aguado, 1855², 4 vols.

CAMPAN, Jeanne Louise, 1825. Tratado de la educación de las niñas según sus diversas edades y condiciones, Barcelona, Biblioteca del Maestro, 2 vols.

CAmpoAmor, Ramón de, 1840. «Los hombres y las mujeres», Diario de Avisos, 4 de enero de 1840 y 10 de enero.

- [1859] 18612. «Prólogo» a La Mujer, de Severo Catalina, Madrid, A. de San Martín, Editor, aum., pp. V-XI. (hay reedición: 1968 Madrid, EspasaCalpe).

CArderera, Mariano, 1852. Guia del Maestro de primera enseñanza, o Estudios morales acerca de sus disposiciones y conducta, con un apéndice sobre la educación de la mujer, Madrid, Imp. de A. Vicente.

- 1854-1858. Diccionario de Educación y Métodos de Enseñanza, Madrid, A. Vicente y Ramón Campuzano, 4 vols. (Hay otras ediciones: 1858-1877², 1883-188633).

- y F. de A. P., [1855] 187228. La Ciencia de la mujer al alcance de las niñas, Madrid, Tip. del Colegio Nacional de Sordo-mudos y de Ciegos.

Carreras y lastortras, Luis, 1859. «La Mujer. Estudios Psicológicos. I. Observaciones Generales», El Café, núm. 26, 2 de octubre.

Catal.ina, Severo, [1859] 18612. La Mujer. Apuntes para un libro, Madrid, A. de San Martín, Editor, aum. (Hay otras ediciones: 1864, 1870, 1876, 1880, $1883,1888,1889,1893,1904,1908,1921,1925,1928,1932,1945$; hay una última reedición: Madrid, Espasa-Calpe, 1968).

1858. La mujer en las diversas relaciones de la familia y de la sociedad. Apuntes para un libro, Madrid, Imp. de Luis García.

- 1857. «El talento en los dos sexos», La Charanga, págs. 74-75.

Cinski, J., 1841. El porvenir de las mujeres, Cádiz. También en: El Nuevo Pensil de Iberia, 30 de abril de 1858 .

C[LARET], [SAN] A[ntonio María], 1846. Avisos saludables a las casadas, o sea Carta espiritual que escribió a una casada hermana suya, por A. C., Vich, Imp. de José Trullás.

CODINA, José, 1846. Pensil de las niñas, o principios de urbanidad y decoro, propios del bello sexo, puestos en verso castellano por José Codina, Manresa, Imp. de Ignacio Abadal.

«Comunicación», Las Novedades, 25 de agosto de 1851.

«Condición de la mujer y su influencia en el orden social», La Floresta, núm. I, págs. 2-3; núm. 2, págs. 9-10; núm. 3, págs. 17-18, 1857. 
Contrarregistro de las mujeres en donde son aforados los defectos de los hombres para hacerles cargo, según factura de cuanto son deudores a la naturaleza. Memoria breve que ofrece un empleado anfibio en obsequio del bello sexo, y en desagravio de las ofensas que le hace el impreso titulado «Registro y. estado de la imperfección, ruindad y malicia de las mujeres», Barcelona, Imp. de la Vda. e Hijos de Brusi, 1822.

C[OоK, C. E.], 1823. «Reflexiones sobre la educación en general», El Europeo, vol. I, núm. 6, págs. 177-188.

Coronado, Carolina, 1846. «Al Sr. Director», El Defensor del Bello Sexo, 8 de febrero, págs. 96-97.

- 1857. «Galería de poetisas españolas contemporáneas. Introducción», La Discusión, núm. 363, 1 de mayo.

CORRADI DE VAN HALEN, Amelia, 1843. «Derechos de la mujer», El Reflejo, núm. 16, pág. 123; al núm. 18, pág. 144.

COSTALES, Manuel, 1852. Educación de la mujer, [s.l.], Biblioteca del Macstro. [CuBí, Mariano], 1849. «Aplicación de las consideraciones sobre la organización de la mujer a su destino y a su educación», La Antorcha, t. I, núm. 27, 10 de marzo, págs. 211-212.

- 1849. «Carácter moral de la mujer», La Antorcha, t. I, núm. 24, 17 de febrero, págs. 189-190; t. II, núm. 25, 24 de febrero, págs. 196-197.

- 1849. «Consideraciones sobre la organización física de la mujer. Su misión», La Antorcha, t. I, núm. 23, 10 de febrero, págs. 181-183.

- 1849. «Costumbres y condición de las mujeres en la Europa moderna», $L a$ Antorcha, t. 1, núm. 18, 6 de enero, pág. 141.

- 1849. «Desarrollo intelectual de la mujer», La Antorcha, t. 1, núm. 26, 3 de marzo, págs. 204-205.

- 1849. «Necesidad de que se instruyan las mujeres lo más y lo mejor posible en armonía siempre con su destino», La Antorcha, t. I, núm. 30, 31 de marzo, págs. 235-237.

D.M.J. de L., 1833. «Prospecto», Correo de las Damas, 3 de junio.

«De la mujer», Noticioso de Ambos Mundos, núm. 155, 15 de diciembre, págs. $1237-1238,1838$.

«Deberes de la mujer con la sociedad», La Elegancia, págs. 140-141, 1846.

«Defensa de las mujeres», Correo de las Damas, núm. 35, 10 de febrero de 1834 , págs. 273-274.

Defensa de las mujeres, La, Madrid, Imp. de J. Hernández, 1846. «Del valor de la mujer», La llusión, 30 de septiembre de 1849.

«Derechos de la mujer», El Reflejo, núm. 16, 20 de abril de 1843, págs. 123-124; núm. 17, 27 de abril de 1843, págs. 134-135; núm. 18, 4 de mayo de 1843, 
págs. 143-144. (Firmado: «Este artículo es debido a la pluma de una señora»).

DEVILLE, Gustave, 1844. «Influencia de las poetisas españolas en la Literatura», Revista de Madrid, t. II, págs. 193, 194, 198 y 199.

Discurso traducido del idioma francés al castellano sobre la proposición siguiente: Qué clase de educación es más propia a la mujer para que procure la felicidad del hombre en sociedad, Madrid, 1821.

«Dos palabras sobre la educación de las mujeres», Correo de las Damas, 20 de abril de 1834.

DUPUY, 1831. Instrucción de un padre a su hija sobre las materias más importantes de religión, costumbres y modo de portarse en el mundo, Barcelona, A. Bergnes y Cía, 2 vols.

«Editorial», La Mujer, 25 de abril de 1852; 30 de mayo de 1852; 6 de junio de 1852.

«Editoriales», El Defensor del Bello Sexo, núm. 1, 14 de septiembre de 1845; núm. 2, 21 de septiembre de 1845; núm. 4, 5 de octubre de 1845; núm. 5, 12 de diciembre de 1845; núm. 7, 26 de octubre de 1845; núm. 19, 22 de marzo de 1846.

«Educación», Gaceta de las Mujeres, 28 de septiembre de 1845.

«Educación de la mujer», Guía del Magisterio, núm. 22, 8 de enero de 1859 , págs.1-2; II, núm. 23,18 de enero de 1859 , págs. 1-2; III, núm. 24,28 de enero de 1859 , págs. $1-2$; IV, núm. 26,18 de febrero de 1859 , págs. $1-2 ; \mathrm{V}$, núm. 29,18 de marzo de 1859 , págs. 1-2; VI, núm. 37,8 de junio de 1859 , págs. 1-3; VII, núm. 56,18 de diciembre de 1859 , págs. 1-3; VIII, núm. 5, 18 de febrero de 1860 , págs. 1-3; IX, núm. 7, 8 de marzo de 1860 , págs. 1-3. (Firmado por «Una profesora»).

«Educación de las mujeres», El Español, 23 de febrero de 1836, pág. 2.

Espejo de las damas y de la juventud o lecciones de todas las virtudes que honran a los dos sexos. Obra extraida de un manuscrito indiano lleno de máximas $y$ de sentencias, Madrid, Imp. José del Collado, 1833.

EL SOLITARIO, 1844. «Me explicaré», El Fénix, 29 de junio. (Sobre la mujer). Establecimiento de educación de señoritas, Madrid, 1848. (Reglamentos de colegios).

ESTELLER, Alejandro, 1866․ Guia de la mujer, o sea Exposición de sus principales deberes y atribuciones, Madrid, Imp. de A. Cubas, 1849; Imp. de Gregorio Hernando.

FENELON [SAlignaC DE LA MOTTE], 1852. La educación de las doncellas, Gerona, Imp. de Grases. (Traducción de J. González de Soto).

Fenollosa, Amalia, 1848. «La mujer», El Cupido y la Luna, núm. 5, págs. 5-6.

- 1844. «La mujer», El Genio, 27 de octubre, págs. 35-36. 
FERrer Del Río, Antonio, 1846. Galería de la literatura española, Madrid, Mellado.

FLORES, Antonio, 1843. «La colegiala», Álbum del Bello Sexo.

FORONDA, Valentín de la, 1801. Carta en que se prueba que todos los entendimientos son iguales, por consiguiente que los de las mujeres son iguales a los de los hombres, y que todos los progresos que se hacen en la literatura $y$ en las ciencias son únicamente efecto de la educación, y de la mayor o menor aplicación, Madrid, Imp. de Cano Munita.

FOurier, 1858. «Opinión sobre las mujeres», El Nuevo Pensil de Iberia, 20 de febrero.

García CAdenA, P[eregrín], 1844. «El bello sexo», El Fénix, 29 de junio.

García Miranda, Vicenta, 1851. «A las españolas», Gaceta del Bello Sexo, 15 de diciembre, págs. 10-11.

GAVILÁN CURTO, Paula, 1859. La niña en el hogar doméstico, o sea nociones de economía y gobierno interior de la casa..., Salamanca, Imp. de J. Atienza.

GAY Y BEYA, Narciso, 1857. La mujer, su pasado, su presente y su porvenir, Barcelona, Imp. Luis Tasso.

Gómez DE Avellaneda, Gertrudis, 1845. «Capacidad de las mujeres para el gobierno», La Ilustración, Álbum de Damas, 2 de noviembre.

- 1843. «La dama de gran tono», Álbum del Bello Secso, También en: Gaceta de Puerto Principe, 20, 22, 24 de agosto de 1844.

GONZÁLEZ AlEGRE, José, 1858. «La mujer, fragmentos de su historia», El Nuevo Pensil de Iberia, 30 de octubre.

GONZALO MORÓN, Fermín, 1844. «Destino de la mujer», Revista de España y del Extranjero, t. IX, págs. 474-480.

GRASSI, Ángela, 1852. «La misión de la mujer», La Mujer, núm. 48, 27 de julio, págs. 3-4.

- 1857. «La misión de la mujer», La Floresta, núm. 5, 7 de junio, págs. 3335.

Guerrero y Pallarés, Teodoro, 1848. Diccionario filosófico del amor y las mujeres, Madrid, Imp. de don Luis García.

«Hombre y la mujer, El», La Moda, núm. 309, 1848.

«Ideología», El Defensor del Bello Sexo, I, 14 de septiembre de 1845, págs. 1-3; II, 21 de septiembre de 1845, págs. 9-11; III, 28 de septiembre de 1845, ppágs 19-20.

ILLESCAS, Barón de, [RAMíREZ DE LOSADA, Nicolás], 1852. «Las eruditas», Semanario Pintoresco Español, págs. 391-392. «Instrucción», El Correo de la Moda, 31 de marzo de 1856.

L. del P., 1833. Defensa del bello sexo contra los que le suponen defectos que verdaderamente no tiene, Zaragoza, Imp. de la Vda. de Mariano Miedes. 
LA ADALIA (seud.),1845. «Educación», El Vergel de Andalucia, 9 de noviembre.

- 1845. «Introducción», El Vergel de Andalucía, 19 de octubre.

LAMENNAiS, F. de, 1843. «Sobre la condición de las mujeres», La Moda, núm. 64, 16 de julio (sin paginar).

«La Mujer imparcial», 1803. «Carta al Diarista acerca de los derechos que debían en la sociedad tener las mujeres», Diario de Madrid, págs. 1249-1250.

LETAMENDI, Agustín de, 1833. Mi opinión sobre la educación de las mujeres. Escrita y dedicada a la Reina N. Sra., Madrid, Imp. de D. Marcelino Calero.

«Literatura», El Buen Tono, 1 de febrero de 1839.

LOPE PElegrín, Juan, 1836. «De las mujeres», El Español, 14 de junio, págs. 3-4.

LÓPEZ, F. M., 1851. «Artículos filosóficos sobre la mujer», Ellas, págs. 9-10.

LLAC I SOlIVAS, Juan, 1849. «Desarrollo intelectual de la mujer», La Antorcha, t. I, núm. 26, 3 de marzo, págs. 204-205.

M.M.V.E., 1833. El triunfo del sexo femenino en junio de 1833 o Defensa de la capacidad de las mujeres para mandar y ser obedecidas, Barcelona, Imp. de A. Bergnes y Cía.

Mad Celnart [BAyle Movillard], 1857. Novisimo manual completo de las señoritas, o de las artes y oficios que les convienen y en que se pueden ocupar, Madrid, Calleja, López y Rivadeneyra, Editores.

MANJARRÉS, José de. Guía de señoritas en el gran mundo, Barcelona, Imp. de T. Gorchs, 1854; Libr. de Juan y Antonio Bastinos, Biblioteca de la mujer, 2, $1876^{2}$; Imp. de J. Jepús, $1885^{4}$ ed. aum. por María de la Peña.

Mañé y Flaquer, Juan, 1845. Pensil del Bello Sexo, Barcelona, Imp. de J.M. de Grau.

MARín, Ángel, 1806. Virginia. O la doncella cristiana: historia útil, que se propone por modelo a las jóvenes solteras que aspiran a la perfección, Madrid, 4 vols. (Traducción de Cayetana Aguirre y Rosales).

Marina, Rosa, 1857. La mujer y la sociedad, Cádiz, Imp. de La Paz.

Martinez Cuende, Eugenio, 1852. «La mujer», Álbum de Señoritas, págs. $163-$ 164 y $171-173$.

Mayoral y Medina, Miguel, 1859. Discurso pronunciado ante el Claustro de la Universidad Central por don..., en el acto de recibir la investidura de Doctor..., Madrid, Imp. Pedro Montero. (Sobre educación física y moral de la mujer).

MENDOZA, Florentina de, 1841. «Manifiesto a las españolas», Gobierno Representativo y Constitucional del Bello Sexo Español, núm. 1, enero, pág. 8. 
MORALES DíAZ, V., 1848. «Influencia de las mujeres españolas», La Luna, págs. $10-11$.

«Mujer con relación al hombre, La», Correo de las Damas, núm. 12, 1835, págs. 89-90.

«Mujer erudita, La», Correo de las Damas, 28 de noviembre de 1835.

«Mujer no es inferior al hombre, La», El Nuevo Pensil de Iberia, 10 de diciembre de 1858.

«Mujeres célebres», La Ilusión, 30 de septiembre de 1849.

Mujeres (Las), su condición, su influjo en el orden social en varios pueblos antiguos y modernos por un amante del bello sexo, Barcelona, Bergnes y Cía., 1831.

OrTIZ, Miguel, 1845. «La mujer», La llustración, Álbum de Damas, 2 de noviembre. También en: La Ilusión, 7 de octubre de 1849.

[OrTIZ, Miguel], 1849. «Prospecto», La Ilusión, 21 de octubre.

- 1850. «Las treinta cosas que constituyen una mujer perfecta», La Ilusión, núm. 9.

PALAU Y FlORES, 1825. La mujer sensible o defensa de su sexo.

PASTOR [PANOR, L. M.], 1839. «La Mujer», El Guardia Nacional, núm. 1117, 30 de enero, págs. 1-2; núm. 1128, 10 de febrero, págs. 1-2.

PASTOR, L. M., 1839. «La Mujer», Panorama, 1 de marzo de 1839 y 24 de enero.

Peiró y MArCo, Jaime, 1859. Escuelas Normales de maestras o sea importancia de la educación de la mujer, Barcelona, Imp. de Ignacio Estevill.

PÉrez, Alicia, 1851. «Aclaración», Ellas, 15 de diciembre.

PéreZ DE CELIS, Margarita, 1857. «Injusticia social», El Nuevo Pensil de Iberia, 10 de diciembre.

PIRAlA, A., 1852. «Educación», Álbum de Señoritas, págs. 9-11 y 65-68.

- 1852. «Educación. La religión y la mujer», Álbum de Señoritas, págs. 7375.

- 1852. «Educación. Necesidad de la instrucción en la mujer», Album de Señoritas, págs. 41-43.

- 1845. «Estudios históricos sobre la emancipación de las mujeres», El Defensor del Bello Sexo, 28 de septiembre, págs. 17-19.

- 1852. «La instrucción en la mujer», Álbum de Señoritas, págs. 1-3.

POTHIER, 1846. Tratado del contrato del matrimonio, Madrid, Victoriano Suárez. Prado y TORRES, Pedro de, 1857. «Ligero estudio a favor del bello sexo», La Floresta, núm. 6, págs. 14-15,; núm. 7, págs. 53-54; núm. 8, págs. 57-58; núm. 9 , págs. 65-66.

«Prospecto», Ellas, 8 de diciembre de 1851.

QUILES, Antonio, 1859. «La mujer», La Verdad, núm. 21, 1 de junio. 
- 1858. «La mujer no es inferior al hombre», El Nuevo Pensil de Iberia, 20 de noviembre; 10 de diciembre.

R. G., 1845. «Educación», Gaceta de las Mujeres, núm. 5, págs. 1-3.

«Religión, moral, deberes mutuos de la familia, influjo de las señoras en la sociedad...», Periódico de las Damas, núm. 1, 1822, págs. 12-18.

RIBOT Y FONTSERÉ, Antonio, 1844. «Educación» [Sección dedicada a], El Tocador, 14 de julio, 28 de julio, 5 de septiembre, 7 de noviembre.

- 1844. «De la mala conciencia», El Tocador, 28 de julio.

RIERA, Joaquín Valentín, 1856. La mujer. Breves rasgos descriptivos de su naturaleza fisica y moral, New York, J. M. and Hamilton.

Ríos, Bernardo de los, 1816. Conducta de la mujer casada, Madrid, Imp. de Álvarez.

Rodríguez Garcia, Vicente, 1845. «A las jóvenes», El Defensor del Bello Sexo, 19 de octubre.

- 1845 y 1846. «Análisis de la mujer», El Defensor del Bello Sexo, 21 de septiembre de 1845 , págs. $11-13 ; 5$ de octubre de 1845 , págs. $25-26 ; 12$ de octubre de $1845 ; 26$ de octubre de 1845 , págs. 53-55; 23 de noviembre de 1845, págs. 85-86; 1 de febrero de 1846, págs. 92-93; 15 de febrero de 1846 , págs. 101-103.

ROMERO LARRAÑAGA, Gregorio, 1839. «La mujer», La Mariposa, pág. 127.

ROUSSEL, M., 1846. El sistema fisico y moral de la mujer, [s.1.].

Ruiz de AlborNoz, Isidro, 1846. «La Mujer», El Defensor del Bello Sexo, 22 de marzo, págs. 142-143.

RUVIANO y SANTA CRUZ, Ventura (trad.), 1845. Misión de la mujer, (La)... o sea influencia sobre la condición politica y social del género humano. Traducida al francés de la novena edición inglesa, por madame Trebicka, y al español por la señorita..., Valencia, Imp. de B. Monfort.

S. LL. S., 1849. «Importancia social de la mujer. Su educación», La Antorcha, t. I, núm. 22, 3 de febrero, págs. 172-173. (Reproduce artículos de Eco de la Frenolojía).

SABATER, Pedro, 1842. «La mujer», El Semanario Pintoresco Español, núm. 4, págs. 115 y 116.

SÁEZ, Gil, 1843. «Influencia de las mujeres en la civilización», El Salmantino, 25 de marzo.

SAGRA, Ramón de la, 1845. «La mujer», La Ilustración, núm. 8, págs. 1-3.

SATORReS, R., 1845 y 1846. «Estudios filosóficos sobre la mujer», El Pensil del Bello Sexo, I, 1845, págs. 49-51; 1846, págs. 73-75.

SiLVA, Micaela de, 1846.»Deberes de la mujer para con la sociedad. Extractado del original francés y adicionado por Micaela de Silva», La Elegancia, págs. 140-141. 
- 1846. «Sobre el matrimonio», La Elegancia, 2, pág. 9.

SinUÉS, Pilar, 1858. «De la influencia de la religión en la mujer», La Linterna Mágica, 2 de mayo, pág. 291.

- 1858. «La mujer (De la importancia de educar y moralizar al pueblo)», $L a$ Linterna Mágica, 31 de enero, pág. 113.

- 1857. «La mujer. Estudios morales», La Moda, págs. 244-249, 278-282, 319-323, 362-266, 411-415 y 456-462.

«Sobre el influjo de las mujeres en la sociedad», Periódico de las Damas, núm. 5,1822 , págs. $1-15$.

«Sobre la educación de las mujeres», Correo de las Damas, 20 de abril de 1834. [Sobre las calumnias de los hombres contra las mujeres], La Mujer, núm. 45, 1852 , págs. $1-2$.

Soriano FuerTes, M., 1857. «Educación de las niñas», El Iris Catalán, núm. 153, 20 de julio, (sin paginar).

SouzA, José de, 1845. «Ideología», El Defensor del Bello Sexo, 14 de septiembre.

STAHL, P.J. [Hetzel, Pierre-Jules], 1858. Lo que son las mujeres o El ingenio de las mujeres y las mujeres de ingenio por... Seguido de la Proclama del Solterón, por don José Vargas Ponce, Madrid, Imp. de la Crónica (Se publicó como folletín de La Crónica a partir de enero de 1858).

T., E[milia] de, 1851. «Defectos de la educación de la mujer», Ellas, págs. 4950.

TAMARIT, Emilia, 1851. «Parte filosófica», Ellas, 15 de diciembre.

- 1852. «Defectos de la educación de la mujer», Álbum de Señoritas, 8 de noviembre.

TrEmBiCKA, Françoise de Tomi, 1845. La Misión de la mujer o su influencia sobre la condición política y social del género humano, Madrid, Libr. Europea. (Traducción del francés de la novena ed. inglesa por Trembicka y al español por la señorita Ventura Rubiano y Santa Cruz).

Triunfo del sexo femenino, El, Barcelona, Imp. de A. Bergnes y Cía., 1833. (Existe otra obra publicada anónima de título semejante: El triunfo de las mujeres, cuyo autor es Juan Ignacio González del Castillo).

«Vanidad de las mujeres, La», El Reflejo, núm. 20, 18 de mayo de 1843, págs. 156-157.

Verdejo y Durán, M. ${ }^{a}$ Teresa, 1854. La estrella de la niñez. Compendio de moral escrito para la educación de las niñas, Madrid, Imp. de «El Buen Sentido», a cargo de M. Morales y Rodríguez.

- 1852. «Las mujeres literatas», La Mujer, t. II, 11 de julio, págs. 3-5.

«Voluntad de las mujeres, La», El Reflejo, núm. 20, 18 de mayo de 1843, págs. 156-157. 